\title{
Development of an Integrated End-To-End Electronic Procurement Management System for Agro-Business in Nigeria
}

\author{
E. Bamidele Ajulo \\ Department of Computer \\ Science. The Federal \\ University of Technology, Akure
}

\author{
R. Olufemi Akinyede \\ Department of Computer \\ Science. The Federal \\ University of Technology, Akure
}

\author{
O. Kehinde Boyinbode \\ Department of Computer \\ Science. The Federal \\ University of Technology, Akure
}

\begin{abstract}
This research is based on developing an integrated end-to-end electronic procurement system for agro-business in Nigeria with the aim of reducing information asymmetry, making agro-business more profitable and attractive by lowering transaction costs. Qualitative findings via structured questionnaire and direct one-on-one interview were carried out among farmers, farmers associations and agro input industries. Microsoft Office Excel was used as a tool to analyze all gathered data. Pinto and Slevin procurement management model was adopted to identify the critical variable of the procurement process and an architecture was designed for the system. Mathematical model of the system was developed, since the developed system is a web based, the client-side was implemented using HTML (Hypertext Markup Language) while the server-side was implemented with Hypertext Preprocessor (PHP) and the database management system used is MySQL. The implementation was done on Intel processor core i3, 1TB Hard Disk and 8GB DDR2 RAM computer system. Functional and performance tests were carried out on the system and the test showed that the system is capable of handling multiple simultaneous users with an average response time of 0.011 to 0.015 seconds.
\end{abstract}

\section{Keywords}

Electronic procurement, end-to-end, agro-business, security

\section{INTRODUCTION}

According to [1], 'procure' means obtaining something with extreme care or effort, while 'purchase' means obtaining something in exchange for payment. Though, procurement management involves many processes and steps and this depends on the organization or firm, but in procurement management, two primary roles are defined - the buyer and the seller [2]. The tradition has been to use set of processes manually to obtain goods or services from outside the organization, but the quest for a process which is more transparent to end-users and improve customer access to suppliers resulted into emergence of electronic procurement systems [3]. Today, the importance of Information Technology (IT) in agriculture cannot be under-estimated and it is viewed that the future of agricultural growth would be information driven [4]. Information within the hands of the farmers means empowerment through control over their resources and decision making process [5]; hence there should be deliberate policies to train and expose farming communities to modern ITs [6].
According to [7], it was discovered that attaining sustainable agricultural development is a worldwide strategic concern and that Information Technologies (IT) have a potential to contribute to achieving significant economic, social and environmental benefits. It means that the adoption of Technological Innovation for sustainable agricultural development is even more so, especially in countries where agriculture is a major livelihood [8]. IT will not necessarily change the lifestyles of the rural communities, rather it will introduce new methods of doing the same traditional activities and/or enable new activities [4].

In the last ten years, the practice of e-procurement has gained popularity, and so has the research on this emerging area; more recent studies have dealt with specific and refined applications of this approach [9]. While some of the early eprocurement technologies are maturing, new ones are appearing, and changing the face of business transactions [10]. According to [11], e-procurement defines the automation of an organization's procurement processes using web-based applications and enables widely dispersed buyers and suppliers to come together; interact, and execute purchase transactions directly over the Internet or Intranet. Eprocurement can be an invaluable tool for enterprises experiencing difficulties in their supply chain to eliminate the associated bottlenecks with existing system [12]. Traditionally, agricultural commodities in Nigeria are procured in major agricultural market in rural areas. Here the middlemen procure from farmers and receive large share of the profits. These middlemen who are at the forefront of the numerous intermediaries in the complex agrarian distribution channel system, are commonly perceived as using unfair means and unscientific methods to judge the quality of the produce that sets the price a farmer would receive [13]. As a result, overtime these practices have served as a disincentive for farmers to invest and produce higher and good quality outputs. The advent of e-procurement will address such concerns by giving farmers an option to sell their produce directly to the higher level of procurement chain and to diminish the impact of the local first level of procurement middlemen [14]. This research work has developed a secure integrated end-to-end e-procurement system that reduced information asymmetry and makes agro-business more profitable by lowering transaction costs and improving agricultural practices. This would contribute to the larger setup of rural development in Nigeria by empowering farmers, an argument well supported by bottom-of-thepyramid theory [10]. The output of this research work would link farmer's communities with potential agro input companies; with the objective of creating efficient supply 
chain aimed at delivering value to numerous customers around the world on a sustainable basis and contributing to rural development in Nigeria.

\section{RELATED WORKS}

Vaidya [15] examined the critical factors that influence eprocurement implementation success in the public sector with the aim of unravelling the critical success factors (CFSs) for successful implementation of e-procurement. In their approach, survey was carried out to examine the literatures for a number of e-procurement initiatives in order to investigate whether a general set of CSFs for e-procurement existed. The literature was used for preliminary investigation into the CSF approach and for finding barriers and implementation outcomes of e-procurement initiatives. While academic articles stimulate and provide theoretical understanding, the focus of their study was to use the practitioner materials (mainly government reports) to capture practitioners' perceptions of e-procurement practices. The CSFs were divided into two factors: human and technology factors. Human factors are those issues that dependent on human behavior and expertise this consists of end-user uptake and training, supplier adoption, business case and top management support while technology factors are those issues dependent on construction and deployment of technology, it consists of system integration and security and authentication. Nevertheless, its limitation is that semi-structured interviews of public sector Procurement managers would have also been considered to capture the perspectives of interviews but which was not possible at the time of the research as a result of time and cost. [12] developed an egovernment procurement (e-GP) system for Nigeria public sector. The research was motivated as a result of great need over the years for the procurement activities of the Nigerian Government to be automated in order to be able to facilitate work effectiveness, efficiency, cost reduction, and increase accountability, and also the increase in the need for the freedom of information and transparency in government projects and activities. The work further examined the drawbacks of existing procurement process in Nigeria with a view to offering an improved approach. A prototype e-GP system was designed to eliminate the associated bottlenecks with existing system and showcase the attendant benefits of the proposed system which can lead to an improved procurement cycle process flow. Primary data were gathered and analysed to determine the procurement work process; however, the research was able to come up with a prototype for the implementation of eGovernment Procurement (e-GP) System for Nigeria Public sector. Akshay [16] examined the Creation of Procurement Efficiencies in Agribusiness in India: Management and Production. The research was borne out of the need to assess the impact and efficiency of e-choupal application system created by Indian Tobacco Company (ITC) for farmers in Indian for procurement of agricultural products. The work examines and evaluates the business model of Indian Tobacco Company (ITC), e-choupal and studies the acceptance level of this application system by the farmers. The data collection was done predominantly through secondary sources and expert interviews were conducted through unstructured method to capture farmers and district manager's perceptions of e-choupal. The result of the findings show a rapidly improving wireless communication and information communication across India in both the rural and urban areas among framers as a result of e-choupal which is dependent on internet facility. Kisumu [8] examined ICCO FED Partners Workshop on Results of ICT Applications in Value Chain Development. The need to improving market access awareness for farmers' and to substantiate their livelihoods through the use of ICTs was a major motivation for this research. The research aimed at linking ICT with agriculture, and incorporating ICT in agricultural sector policies and programmes. All the information to sustain and increase agricultural production that is spread over different agencies, notably farmers, universities, research institutes, extension services, commercial enterprises, and Non-Governmental Organizations (NGOs) which were poorly documented or hard to access were gathered using external hard drives, scanners and photocopier. The information were properly documented for it to be timely available in appropriate formats either in hardcopy form or in stand-alone databases. The Information in which some were videos in local languages was presented and arranged in an appropriate format in order to be effectively used by rural communities. The work has demonstrated that proper deploy of ICT can enable rural communities to interact with other stakeholders, and thus reducing social isolation.

\section{MISCONCEPTIONS ABOUT WHAT E-PROCUREMENT IS AND WHAT IS NOT}

There have been many misconceptions about e-procurement. E-procurement has many different definitions in the marketplace, and is still confused with EIPP (electronic invoice presentation and payment), $\mathrm{P} 2 \mathrm{P}$ (procure to pay), and e-payment (electronic payment) - but none of these technologies comes close to implementing the full procurement cycle. It is also sometimes confused with, or thought to include electronic auction which is, in fact, part of the e-sourcing cycle; and sometimes also thought to be contract management, another major component of the esourcing cycle [17].

True e-procurement is the enablement of the full procurement cycle from initial requisition to final payment (Figure 1.0). It includes support for the location of the required good or service, the necessary authorizations, generation or acceptance of goods receipt, invoice processing, e-payment, payment acknowledgement, and analysis and reporting [13].

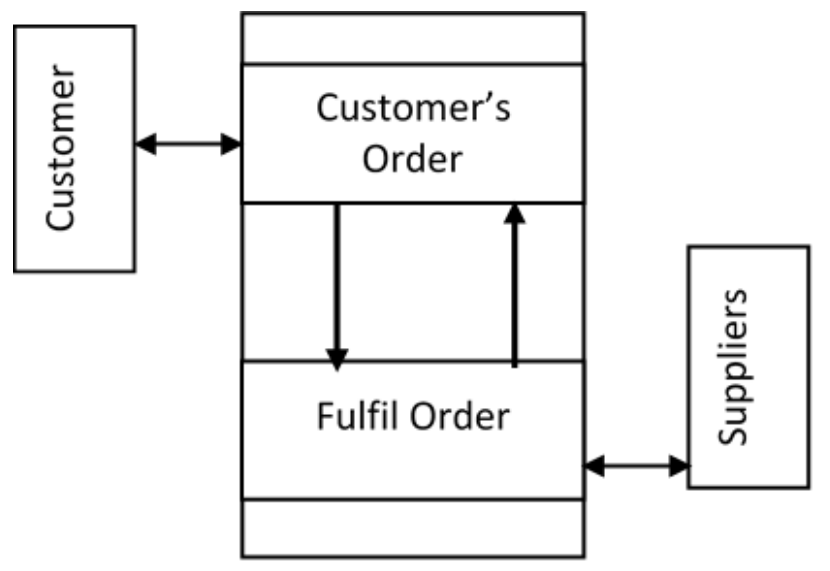

Figure 1.0: e-Procurement marketplace 


\section{TRADITIONAL PROCUREMENT PROCESS FOR AGRICULTURAL PRODUCE}

In Nigeria, farmers face several problems in relation to the cultivation, harvesting, the sale of the produce and getting the right price for their produce [18].

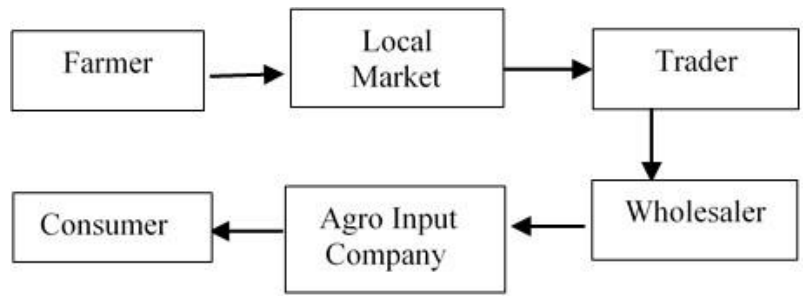

Figure 2.0: Traditional Procurement Process (Source: adapted from [19])

Figure 2.0 shows the process where the farmers harvest the crop and bring their produce to local market which happens multiple times around the year in small batches. The supply chain consists of many intermediaries and with every intermediary the cost of produce increases for the final product at each level. With the middlemen adding their profit margin to the cost, the farmers receive the least return on their produce in the entire value chain. E-procurement process would ensure smooth flow of information to the farmers by dislodging most of the middle men from the chain of information flow. It would provide a virtual market place where farmers can directly make transaction with procurer.

\section{INTEGRATED END-TO-END E- PROCUREMENT}

Without integrated end-to-end e-procurement, it is difficult to realize the benefits that e-procurement has been promising, and often failing to deliver since its inception in the nineteen nineties [17]; for any organization to derive optimal benefit from the implementation of e-procurement it has to be tailored and integrated into the organization procurement process. Integrated end-to-end e-procurement is the implementation of e-procurement technologies that support each step of the various procurement cycles of an organization or industry in a tightly integrated fashion; integrated end-to-end eprocurement brings with it a host of benefits that improve process efficiency, increase organizational effectiveness, facilitate collaboration with suppliers, and optimize control over demand and spend.

\section{THE PROPOSED SYSTEM NODEL}

\subsection{The System Protocol}

Protocols were introduced into the system for preliminary registration process of users in other to prevent eavesdropping, and fraudsters that might want to impersonate the system. According to the design, buyer b and suppliers $s$ details must be inputted on the system during registration before they can engage in transactions. The system generates a trustworthiness document to both buyer $b$ and supplier $s$ before they can transact business via the application.

\subsection{Supplier's Registration Process}

This is the first step for suppliers' registration. The supplier s clicks on register new user and supplies his details. The system would process the supplier details for registration and send confirmation in form of cipher text. If the registration fails, an error messages would be displayed. The system would prompt the supplier to go through the process again.

If the supplier s has already registered, he would login and then, the login would be validated. After this, the interface would be updated appropriately. The information required to be provided by the supplier during registration includes supplier's initial request, registration form request, and company registration details. Section 6.3 is the suppliers' registration algorithm.

\subsection{Corresponding Algorithm - Supplier Registration Scheme}

Get Supplier Information

IF Supplier has been Registered THEN

Supplier begin login procedure

Validate login for Supplier

IF Supplier login detail is correct THEN

Update interface appropriately

ELSE

Output error message

Return to login point

IF Supplier is new to the Site THEN

Register Supplier

Process Supplier details

IF Registration is Successful THEN

Output Success Message

Send Confirmation Information

ELSE

Output Error Message

Return Supplier to start Registration again END

END 


\subsection{Buyer's Registration Process}

The system checks for a buyer $\mathrm{b}$ registration during login. If $\mathrm{a}$ buyer $\mathrm{b}$ has not registered, the system prompts him to register; the buyer $\mathrm{b}$ completes and submits the form. The system will process the registration form, (if successful), sends a confirmation of registration to the buyer $b$. If the registration fails, error messages would be displayed and the system will prompt the buyer $\mathrm{b}$ to go through the process again. However, if buyer $\mathrm{b}$ has already registered, the buyer $\mathrm{b}$ will login and his login information will be validated. After this, the interface will be updated appropriately. Section 6.5 is the buyers' registration algorithm.

\subsection{Corresponding algorithm - Buyer Registration Scheme \\ Get Buyer Information}

IF Buyer has been Registered THEN

Buyer begin login procedure

Validate login for Buyer

IF Buyer login detail is correct THEN

Update interface appropriately

ELSE

Output error message

Return to login point

IF Buyer is new to the Site THEN

Register Buyer

Process Buyer details

IF Registration is Successful THEN

Output Success Message

Send Confirmation Information

ELSE

Output Error Message

Return Buyer to begin Registration again

END

END

END

END

\subsection{System Mathematical Model}

A mathematical model for the e-procurement system was developed by assuming $s_{1}, s_{2}, \ldots, s_{\mathrm{k}}$ to be the suppliers (farmers) that are ready to sell on the Internet and also that a buyer, $b_{n}$ faces a choice of $X_{n}$ commodities labeled $1,2, \ldots, n$ each with a market price $p_{1}, p_{2}, \ldots, p_{n}$. The buyer $b$ is assumed to have a function $U$, depending on the amounts of commodities $\mathrm{X}_{1}, \mathrm{X}_{2}, ., X_{a}$ to be procured by the buyer $b$, such that $X_{b} \epsilon_{X_{n}}$. The model further assumes that the buyer $b$ has a credit card limit of $L$ which is used to purchase a commodities $\mathrm{X}_{1}, \mathrm{X}_{2}, \ldots, \mathrm{X}_{a}$ in such a way as to maximize $U\left(\mathrm{X}_{1}, \mathrm{X}_{2}, \ldots, \mathrm{X}_{b}\right)$. Since every buyer will want to maximize his purchasing power, therefore, this equation thus holds; that is:

$$
\max U\left(X_{1}, X_{2}, X_{3}, \ldots \ldots, X_{\mathrm{i}}\right)
$$

Subject to:

$$
\sum_{a=1}^{\mathrm{n}}\left(\mathrm{X}_{a} P_{a}\right) \leq L
$$

$$
\text { for all } X_{a} \geq 0 \quad \forall a \in\{1,2,3, \ldots \ldots \ldots, n\}
$$

Let summation of $X_{j}$ equals total number of items procured for (e.g. $\sum X_{j}=$ total number of items ordered for). The engaging participants involved in the payment scheme are hereby expressed further.

$$
s_{\text {procured paid }}=b_{\mathrm{ab}} \sum_{a=1}^{\mathrm{k}} s_{a} \sum_{b=1}^{n} X_{b} P_{b}
$$

Where $P_{a}$ are the items to purchase and $S_{a}$ are the suppliers.

$\left(X_{b} P_{b}\right)$ is the list of farm produce that are ordered for by the potential buyer $b_{n}$,

$$
\text { where } X_{b}=\mathrm{X} \text { and } P_{b}=P
$$

\subsection{System architectural design}

The system architectural design was done based on the formulated procurement work flow, the user requirements and security features. The system architecture is a comprehensive model upon which the application is built; the model is in three segment such that the client (buyer) can work offline using the procurement application by connecting to the system server, as well as connect online via the web server to communicate with prospect suppliers/farmers and financial institution for payment; while the suppliers/farmers can only connect to the procurement application using their web browser via the internet. Figure 3.0 shows the architectural model for the secure integrated end-to-end electronic procurement management system.

\subsection{Unified Modeling Language (UML)}

The Unified Modeling Language (UML) is a general-purpose, developmental, modeling language that is intended to provide a standard way to visualize the design of a system. Here, a Use Case is used to formally described the functionality that the system will have when constructed. Each Use Case describes the functionality to be built in the proposed system; generally Use Case diagrams graphically depict the interactions between the system and external system users. It graphically decides who will use the system and in what ways and capacity the user expects to interact with the system. In figure 4.0, the use case diagram illustrates system requirements of one of the user of the e-Procurement system, for example, a farmer. The farmer can interact with the system in the following ways: he can register to use the system, upload a proposal as well as update it, response to the new contracts if interested by sending bid documents, access related information associated with new contracts, view approved contract, track and monitor the status of his contract, and send progress reports as the goods are being executed and delivered. Figure 4.0 shows the Use Case of user Requirement diagram for the system. 
Figure 5.0 shows the class diagram for e-Procurement System that consists of classes of the system, their interrelationships and the methods, and attributes of the classes. The procuring entity for instance can accept farmers, reject farmers, accept supply, reject supply, and approve supply. The farmers on the other hand, can bid for contracts, update profile, download contract document from the database.

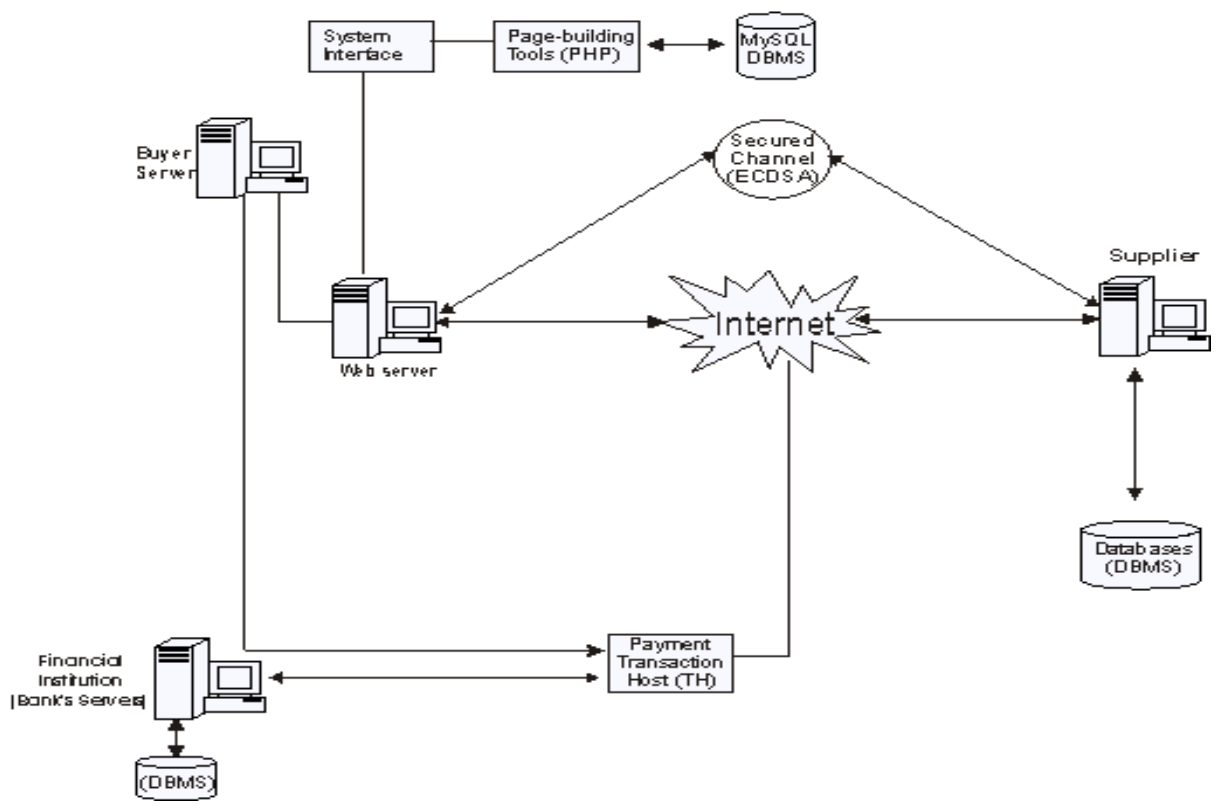

Figure 3.0: Proposed Model of a Secure Integrated End-to-End e-Procurement Management System for Agro-Business

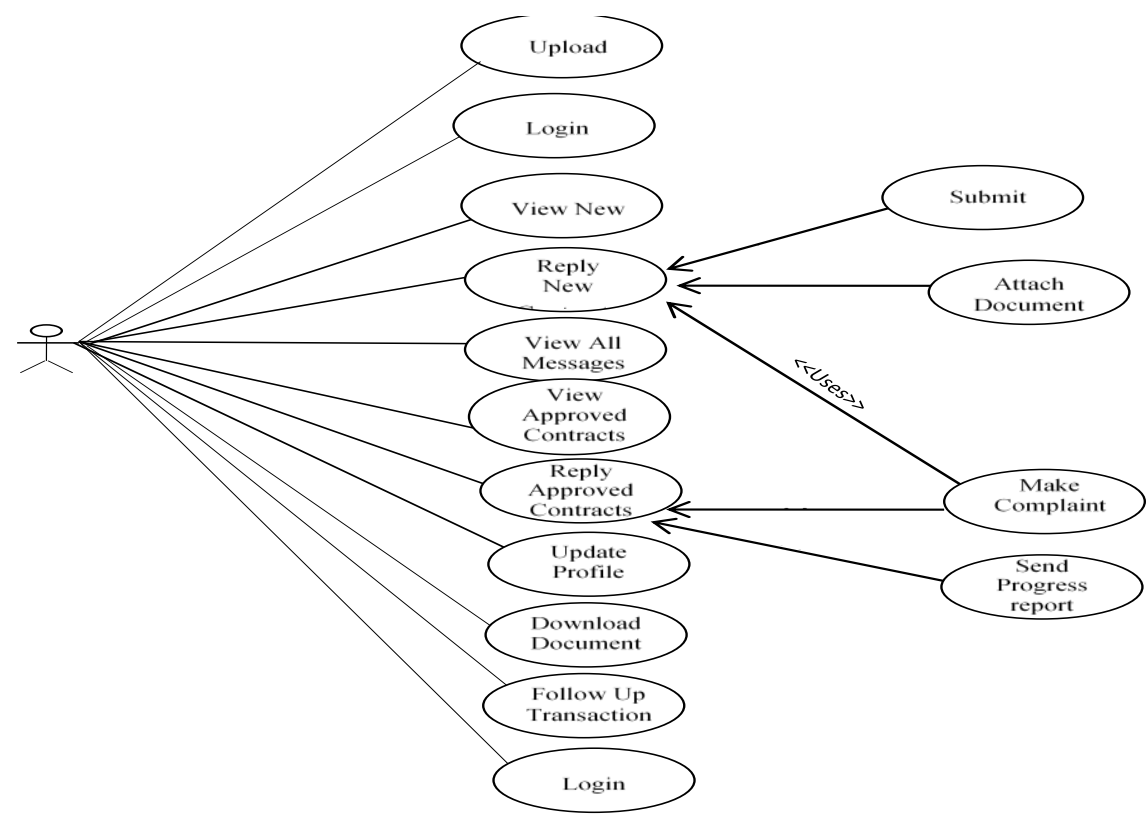

Figure 4.0: Use case of user requirement diagram 


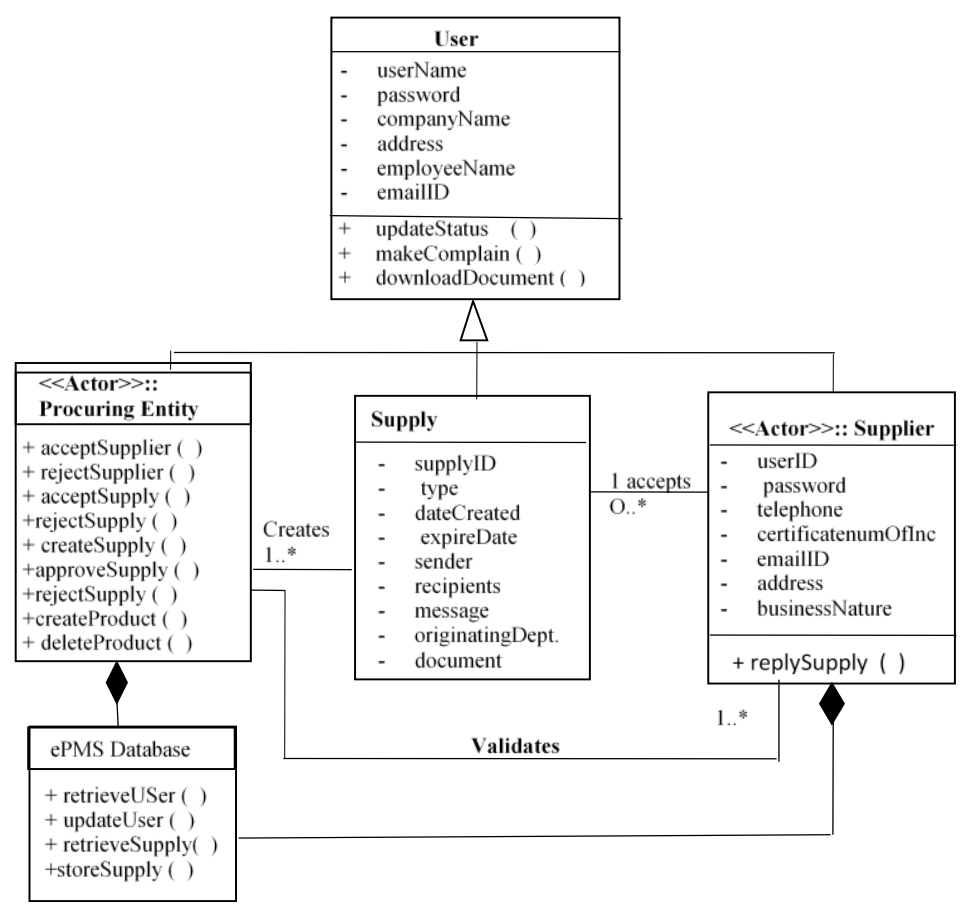

Figure 5.0: Class diagram for e-procurement management system (e-PMS)

\section{SYSTEM IMPLEMENTATION}

\subsection{Registration and Login Interface}

The e-Procurement system model describes the working procedure of customers and buyers. The scenario starts with a demand from users (buyer or customer) to use, send, modify or upload data in the e-Procurement environment. The system requests from the user to create accounts if he is not a registered user. The user fills the account form to get an approval from the system to be a registered user. During the creation of account, the client is issued a username and password key. This detail is used as pre-identifier for user during navigation and usage of the system. The password key which occurs during the account creation represents one time password, and generates each login time by the user into the system. The details is as shown in Figure 6.0.

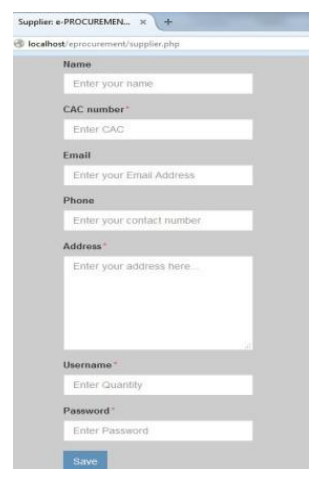

Fig. 6.0: Showing the User Registration Interface

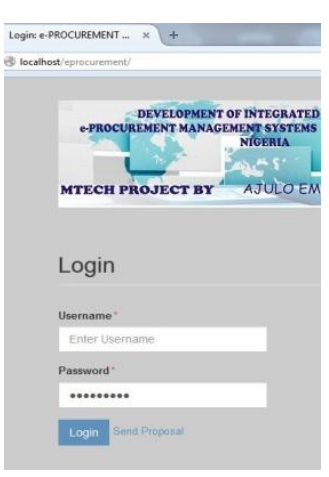

Fig. 7.0: Showing the Login Interface
To send a message by (any of) the user, the user hashes the message to generate a message digest. This message is encrypted (signed) by the client. The encrypted message is send via the e-Procurement platform. The receiver gets the message and identifies the client based on the public key and verifies the message's authenticity using the authenticator's public key. Figure 7.0. shows the system login interface.

\subsection{Configuration module}

The following setup would need to be carried out before performing any process: Products, Business Partners (Farmers and Suppliers) and Price configuration.

i. Products: it needs to be configured prior any purchase requisition is issued. Each product that is to be purchased needs to have a price in the purchase price list in order to be selectable in any transactional document like a purchase order or a purchase invoice.

ii. Business Partners (Farmers and Suppliers): it needs to be configured prior any purchase requisition and can automatically turn into a purchase order.

Of important note is that one may not require performing any additional setups for the Procurement Management application area. The sample data can be set already to contain the roles, business partners, products, warehouse/logistics and prices pre-configured. Figure 8.0, Figure 9.0 and Figure 10.0 show the Users Account, Product and Supplier configuration interface. 


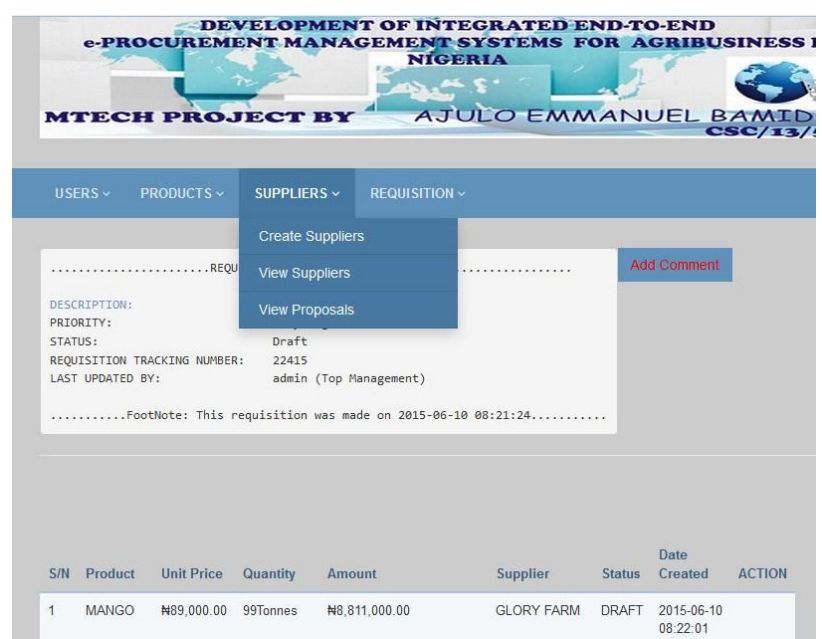

Figure 8.0: Users Account Configuration Interface

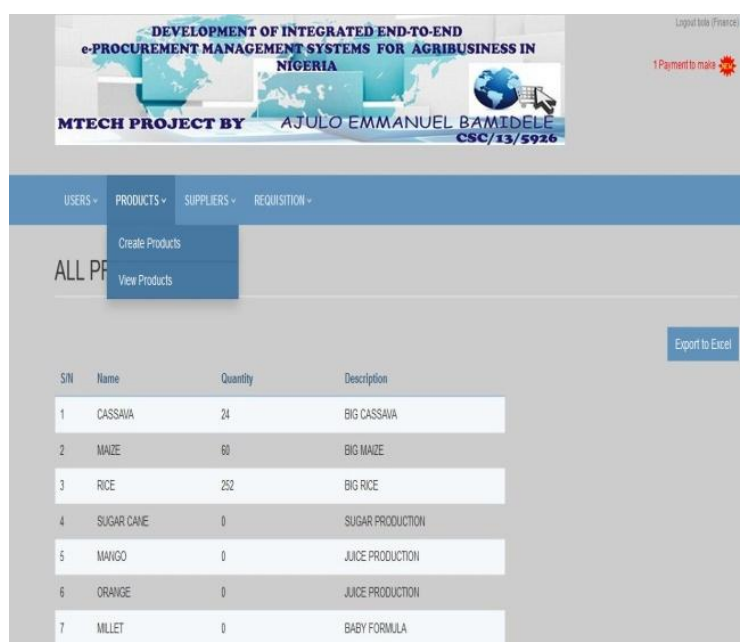

Figure 9.0: Product Configuration Interface

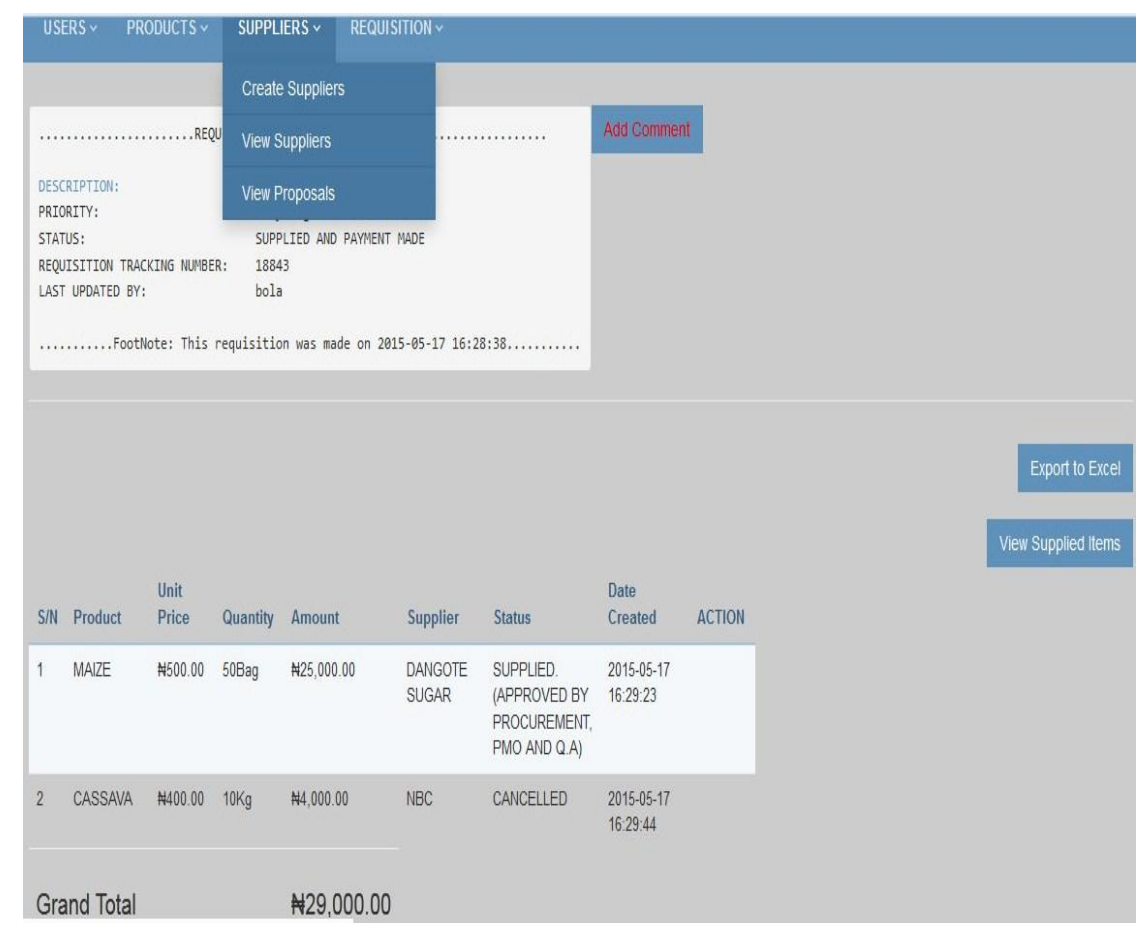

Figure 10.0: Supplier Configuration Interface

\subsection{Procure to Pay Module}

This module manages the life-cycle of the procurement process. Due to its complexity and different roles involved, it is convenient to split 'Procure to Pay' down into two main sub-processes:

i. Requisition to Receipt: process starts by the creation and management of purchase requisitions and corresponding purchase orders to the moment the logistic (warehouse) staff receives the merchandise.

ii. Supplier Invoice to Payment: continues previous subprocess by registering the supplier invoices and closes it by paying supplier invoices.

In a succinctly manner, the Procure to Pay business (menu) process is executed as follows:

i. Any member of the organization allowed to do so can directly issue a Requisition (in this case, the factory/production unit) as a result of an organization or business unit needs.

ii. The requestor creates a new document in the Requisition window, enters a "Need by date" and then looks for the product or service needed. If the product does not exist it can be entered at that time in the Product window.

iii. The requestor continues by adding for each product needed by date, the product, the quantity, the price if known and if needed its attribute (size and/or breed, etc). A preferred supplier can also be added if known.

iv. Once done, the requisition is saved in "Draft" status; it could be changed later on by the Production Management Office (PMO) if needed.

This requisition notifies the Production Management Office (PMO) of products to order, their quantity and the time frame for its delivery. The Production Management Office (PMO) 
processes it and forwards it to the procurement officer who is now in charge of managing already created purchase requisitions. Figure 11.0 and Figure 12.0 show the Requestor and Production Management Office (PMO) Interface respectively.

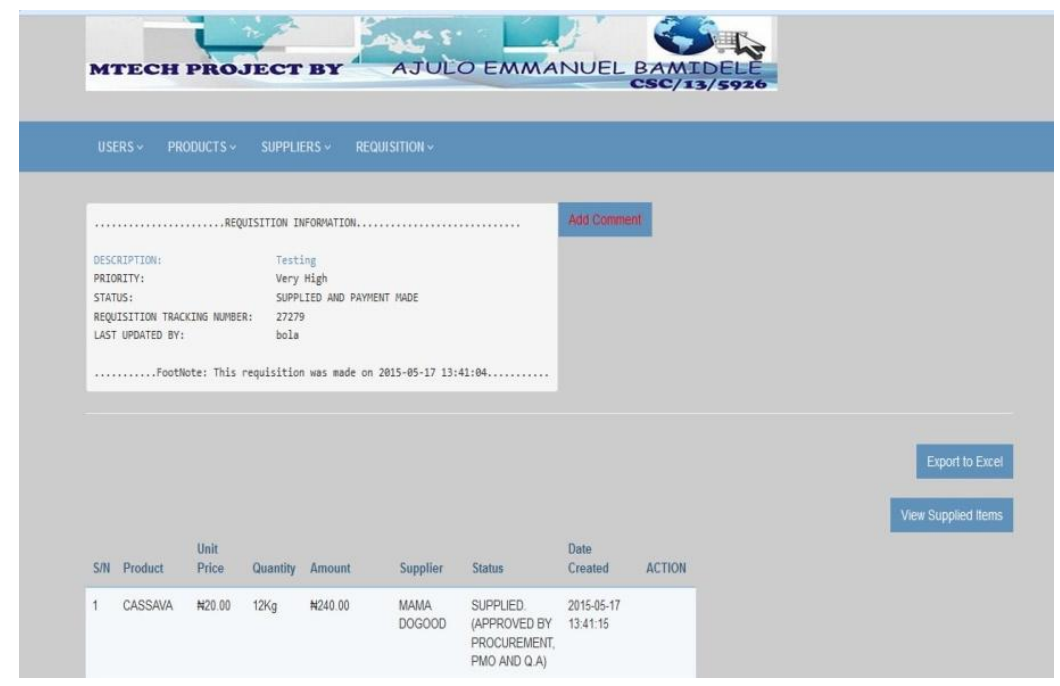

Figure 11.0: Requestor Interface

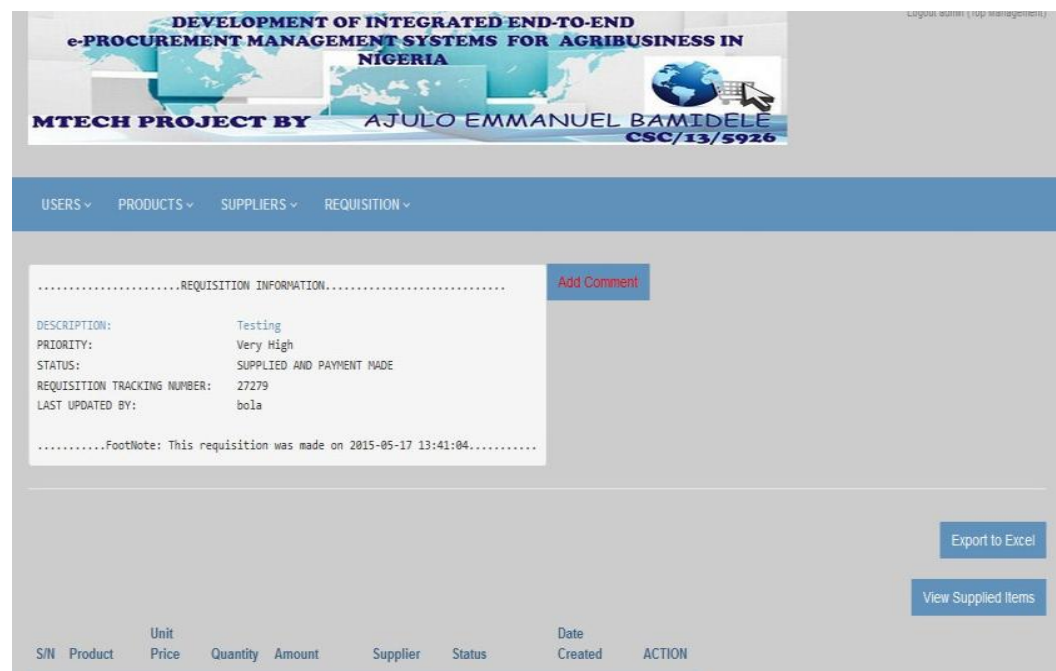

Figure 12.0: Production Management Office (PMO) Interface

\section{CONCLUSION}

The research has developed a robust and integrated end-to-end e-procurement system for agro-business in Nigeria with the aim of reducing information asymmetry, making agrobusiness more profitable and attractive by lowering transaction costs. The system has the capability of deploying an e-Procurement Management System with improved performance in computing power and battery resource usage. It would also promote confidence in both large and small scale organization in the use of e-Procurement Management System most especially in the agro-business in Nigeria. The procurement survey that was carried out enabled a wellintegrated e-Procurement system to be developed. This system would link farmers closely with potential agro input companies and create efficient supply chain aimed at delivering value to numerous customers around the world on a sustainable basis and to contribute to the rural development in Nigeria. Finally, the developed e-Procurement system will lead to improve market value for farmers and their products.

\section{ACKNOWLEDGMENT}

The author would like to express his gratitude to Department of Computer Science, The Federal University of Technology, Akure for the support and facilities provided.

\section{REFERENCES}

[1] Oxford Dictionary, (2016), http://www.oxforddictionaries.com/definition/english/pro cure

[2] PMBOK, (2013), A Guide to Project management body of knowledge, Project Management Institute, 5th Edition. PMI, USA.

[3] K. Kejuo, (2012), Critical Success Factors: Telecommunication Network Equipment Procurement Projects. A case study of MTN Nigeria, Master of Science in Project Management and Operational Development thesis submitted to Royal Institute of Technology, Vetenskap. 
[4] M. Omaku and A, Oyigbenu, (2012), "ICT Phobia and its Sociological Imperatives to Agriculture in Nigeria", Journal of Agriculture and Veterinary Sciences, Volume Journal of Agriculture and Veterinary Sciences 4, December 2012, 2012 Cenresin Publications. Oxford Dictionary Reversed Edition, (2012)

[5] N. Neelameghan, (2006), E-communities, Community Knowledge Management International Journal of Technical Communication 1(2) 21 - 27.

[6] T. Iorliam, E. Imbur and P. Iortima, (2012), "Adoption of information and communication technologies as source of information on agricultural innovations among farm households in Nigeria: evidence from Benue state", International Journal of Development and Sustainability, Vol. 1 No. 3, pp. 924-931.

[7] E. Gelb, A. Maru, J. Brodgen, E. Dodsworth, R. Samii and V. Pesce, (2008) "Adoption of ICT Enabled Information Systems for Agricultural Development and Rural Viability" Pre-Conference workshop summary: ICT Adoption Workshop at the IAALD-AFITA-WCCA Conference 2008 GFAR

[8] T. Kisumu, (2012), "ICCO FED partners workshop on results of ICT applications in Value Chain Development" IICD/ICT 4D EffectS/Youth, ICTs and Agriculture, pg. 4

[9] T. Schoenherr, and V. Tummala, (2007), "Electronic Procurement: A Structured Literature Review and Directions for Future Research," International Journal of Procurement Management, Vol. 1, No. 1/2, 2007, pp. 837

[10] C. Prahalad, (2009), "We must see India and Bharat as one", Forbes India, interview by Neelima MahajanBansal.

[11] R. Shirzad and D. Bell, (2013), A Systematic Literature Review of Flexible e-Procurement Marketplace. Journal of Theoretical and Applied Electronic Commerce Research ISSN 0718-1876 Electronic Version vol 8 / issue 2 / August 2013 / 49-70.
[12] A. Adebiyi, C. Ayo, O. Akinusi and M. Adebiyi, (2010), "Design and Implementation of Electronic Government Procurement (e-GP) System for Nigeria Public Sector", International Journal of Electrical \& Computer Sciences IJECS-IJENS Vol. 10 No. 6

[13] B. Bowonder, V. Gupta and A. Singh, (2007), Developing a Rural Market e-hub, The case study of eChoupal experience of ITC, Socio-Economic Report Planning Commission Study-ICT4. Retrievedfrom http://planningcommission.nic.in/reports/sereport/ser/stdy ict/4 e-choupal\%20.pdf, 2007.

[14] R. Anupindi, and S. Sivakumar, (2006), Supply chain reengineering in agri-business - A case study of ITC's eChoupal, in H. Lee and C.-Y. Lee (Eds.), Supply Chain Issues in Emerging Economies, Handbooks in Operations Research and Management Science, Elsevier-Springer, 2006.

[15] K. Vaidya, A. Sajeev, and G. Callender, (2008), Critical Factors That Influence E-Procurement Implementation Success in The Public Sector, Journal Of Public Procurement, Volume 6, Issues 1 \& 3, 70-99

[16] T. Akshay, G. Prashant and S. Sunanda, (2012), "Creating Procurement Efficiencies in Agribusiness in India", Management and Production Engineering Review, Volume 3, Number 3, September 2012, pp. 63 70 DOI: $10.2478 / \mathrm{v} 10270-012-0025-\mathrm{x}$

[17] Enporion and Sourcing Innovation (2008), Integrated End-to-End e-Procurement: The foundation of spend management success", www.enporion.com, www.sourcinginnovation.com

[18] N. Gorla, (2008), Hurdles in rural e-government projects in India: lessons for developing countries, Electronic Government: An International Journal, 5, 1, 91-102, 2008.

[19] C. Parker, K. Ramdas and N. Savva, (2011), "Is IT Access Enough? Evidence from a Natural Experimenting India's Agriculture Markets”, 2011. 